\title{
Vorrede.
}

Bei dem ungemein regen Interesse, welches in der heutigen Zeit in weiten Kreisen für die orientalische Theosophie und Mystik herrscht, kann es nicht wunder nehmen, daB der erste Band der "koptisch-gnostischen Schriften" 1 im Buchhandel vergriffen ist. Ich erhielt deshalb vom Verlage den Auftrag, die Pistis Sophia, auf welche sich das Hauptinteresse der Leser konzentriert, in neuer Bearbeitung herauszugeben, und kam dieser Aufforderung um so freudiger nach, als ich zugleich mit der Neuherausgabe des koptischen Textes für die Serie der Coptica betraut war, die mit Unterstützung des Institutum Rask-Oerstedianum in Kopenhagen unter der Leitung von Professor H. O. Lang e veröffentlicht werden. Diese Ausgabe ist soeben erschienen unter dem Titel: Pistis Sophia. Neu herausgegeben mit Einleitung nebst griechischem und koptischem Wort- und Namenregister von D. Dr. Carl Schmidt (Coptica II), Hauniae, Gyldendalske Boghandel-Nordisk Forlag, 1925. Die Bearbeitung des koptischen Textes mußte natürlich auch der Übersetzung zugute kommen: vor allem wurde mir durch ein Reisestipendium von seiten der Notgemeinschaft der Deutschen Wissenschaft die Möglichkeit gegeben, das Ms. noch einmal an Ort und Stelle einzusehen und eine Reihe von Problemen von neuem zu überprüfen. Ich fühle mich daher verpflichtet, Herrn Staatsminister Dr. Schmidt-0tt für die Unterstützung auch an dieser Stelle meinen besonderen Dank auszusprechen.

Eine Vergleichung der jetzigen Ausgabe mit der früheren wird zeigen, daß die Übersetzung an zahlreichen Stellen eine Verbesserung erfahren hat, aber tiefgreifende Änderungen sind

1 In der Sammlung Die Griechischen christlichen Schriftsteller der ersten drei Jahrhunderte, Leipzig 1905. 
nicht erfolgt. Freilich ist der textkritische Apparat weggelassen, da dieser nur die wenigen Kenner des Koptischen interessieren wird and diese in der Textausgabe das Material vorfinden. Leider mußten infolgedessen auch manche gelehrte Notizen ausgemerzt werden und alle koptischen Ziffern und Wörter bei der Beschreibung der Handschrift verschwinden, da der Verlag das gröBere Laienpublikum als Käufer in erster Linie berücksichtigt wissen wollte. Von diesem Gesichtspunkt aus habe ich eine eingehende Analyse des Inhalts behufs Einführung in die vorliegende gnostische Gedankenwelt hinzagefügt. Ebenso sind die Untersuchungen über Verfasserschaft und Zeit der Entstehung des Werkes bedeutend erweitert. Auch die Fragen und Probleme über Handschrift, Sprache und Komposition sind ausführlicher behandelt; ich habe letzteren Teil fast unverändert in die Übersetzungsausgabe übernommen. Auf religionsgeschichtliche Untersuchungen habe ich mich nicht eingelassen, obwohl die Pistis Sophia zahlreiches Material dazu bietet. ${ }^{1}$ Trotzdem hoffe ich auch den Kirchen- und Religionshistorikern manches Neue sagen zu können. So möge denn diese Übersetzungsausgabe in ihrem neuen Gewande neben den alten Freunden neue Liebhaber für die uns heute so seltsam anmutende gnostische Literatur gewinnen!

Berlin, im Januar 1925.

\section{Carl Schmidt.}

1 Ich verweise Interessenten auf Liebleins Abhandlung ${ }_{n}$ Pistis Sophia in den Kristiania Videnskobs-Selskabs Forhandlingen 1909 and dazu Maspero, Revue critique 1909, p. 192 . Ohne Wert sind die Ausführungen von Amélineau in seinem Essai sur le Gnosticisme égyptien, ses développements et son origine égyptienne [Annales du Musée Guimet, t. XIV], Paris 1887. 


\section{Bemerkungen zur vorliegenden Ausgabe.}

Da inzwischen mein e Neuausgabe des koptischen Textes erschienen ist, sind die betreffenden Seiten am Rande mit schrägen Ziffern angegeben; die geraden Zahlen bedeuten die Seiten der Ausgabe von Schwartze-Petermann.

Die alte Kapiteleinteilung habe ich beibehalten, ebenso die Zerlegung der Psalmen und Hymnen in Verse. Die griechischen Wörter sind in Klammern beigesetzt, um dem Leser die griechische Grundlage der koptischen Übersetzung vor die Augen zu führen. Freilich habe ich den griechischen Index nicht wieder anfgenommen, da der Gelehrte ihn in meiner Textausgabe benutzen kann. Aus dieser Rücksicht auf das interessierte gebildete Laienpublikum sind die textkritischen Anmerkungen, wie ich in der Vorrede bereits bemerkt habe, fast ganz ausgemerzt. Die alt- und neutestamentlichen Parallelen sind dagegen angemerkt worden. Auch auf ein ausführliches Namen- und Sachregister glaubte ich nicht verzichten zu dürfen, um dem Erforscher des Gnostizismus und dem Religionshistoriker die Benutzung der Ausgabe als eines Nachschlagewerkes zu ermöglichen.

Was die Zeichen betrifft, so bedeutet:

\langle\rangle$=$ auf Konjektur beruhender Zusatz,

$[\mathrm{]}=\mathrm{zu}$ beseitigender Einschub,

$* * *=$ Lücke,

? = zweifelhafte Übersetzung. 